\title{
PERBANDINGAN POWER SPECTRAL DENSITY SISTEM OWDM DAN OFDM PADA KANAL RAYLEIGH
}

\section{COMPARISON OF OWDM AND OFDM POWER SPECTRAL DENSITY OVER RAYLEIGH CHANNEL}

\author{
Yuyun Siti Rohmah ${ }^{1}$, Ali Muayyadi², Rina Pudji Astuti \\ ${ }^{1}$ Prodi D3 Teknik Telekomunikasi, Fakultas Ilmu Terapan, Universitas Telkom \\ ${ }^{2,3}$ Prodi S1 Teknik Telekomunikasi, Fakultas Teknik Elektro, Universitas Telkom \\ ${ }^{1}$ yuvunsr@tass.telkomuniversitv.ac.id, ${ }^{2}$ alimuavvadi@telkomuniveristv.ac.id, \\ ${ }^{3}$ rinapudiiastuti@telkomuniversity.ac.id
}

\begin{abstract}
Abstrak
OFDM (Orthogonal Frequency Division Multiplexing) merupakan teknik modulasi multicarrier untuk mengatasi permasalahan kanal multipath seperti frekuensi selektif fading. Orthogonalitas pada sistem OFDM menghasilkan banyak sub-carrier yang dapat ditransmisikan secara bersamaan pada spektrum frekuensi yang terbatas tanpa saling berinterferensi. Efesiensi bandwidth didapat karena masing-masing sub-carrier saling orthogonal sehingga antara sub-carrier yang berdekatan dapat dibuat overlapping. OWDM (Orthogonal wavelet division multiplex) merupakan suatu sistem multicarrier alternatif dari OFDM dan telah diteliti sebagai kandidat yang dapat diaplikasikan pada wireless communication. Sistem OWDM menggunakan Inverse Discrete wavelet transform (IDWT) sebagai pembangkit subcarrier-subcarrier yang saling orthogonal dan berfungsi sebagai modulator. Sedangkan DWT (Discrete Wavelet Transform) digunakan sebagai demodulator. Penelitian ini membandingkan power spectral density dari sistem OWDM dan OFDM. Dari hasil simulasi perbandingan power spectral density (PSD) didapatkan bahwa PSD dari masing-masing sistem sama. Pada OWDM, pembagian band frekuensi untuk setiap sub-band berbeda kecuali sub-band pada level yang sama. Semakin tinggi level sub-band maka semakin lebar band frekuensinya.
\end{abstract}

Kata kunci : OFDM, OWDM, power spectral density

\begin{abstract}
Orthogonal Frequency Division Multiplexing (OFDM) is a multicarrier modulation technique to mitigate the problem of multipath channel such as frequency selective fading .Orthogonality in OFDM provides any sub-carrier that be transmitted simultaneously over limited of frequency spectrum. Bandwidth effeciency to be obtained because between adjacent sub-carriers can be made overlapping and orthogonal of each other. OWDM (Orthogonal wavelet division multiplex) is alternative system of OFDM and it has been proposed as a candidate that can be implemented in wireless communication. OWDM used Inverse Discrete wavelet transform (IDWT) to generate orthogonal subcarriers and it also as modulator. While DWT (Discrete Wavelet Transform) is used as a demodulator. This paper compared the power spectral density (PSD) of OWDM and OFDM system. Simulation resulted the comparison of both system is same, but the division of each sub-band is different in OWDM system except for sub-band in the same level. The highest level have more a wide bandwidth.
\end{abstract}

Keywords: OFDM, OWDM, spectral density 


\section{PENDAHULUAN}

Kemudahan akses informasi untuk mendukung beragam aktivitas manusia sangat diperlukan untuk mendukung perkembangan teknologi telekomunikasi seperti pada saat ini. Maka dari itu dibutuhkan sistem komunikasi wireless yang mendukung aktivitas mobile user yang dapat menyediakan layanan data berkecepatan tinggi. OFDM adalah salah satu teknik multicarrier yang bisa digunakan untuk memenuhi kebutuhan tersebut karena utilitas spektralnya yang efisien dan juga ketahanan terhadap frekuensi selective fading. Hal ini dikarenakan penggunaan sub-carrier saling orthogonal sehingga memungkinkan sub-carrier saling overlapping.

Selain OFDM, sistem multicarrier berbasis transformasi wavelet telah diajukan dan diberinama Orthogonal Wavelet Division Multiflexing (OWDM). Teori wavelet telah diramalkan oleh beberapa penulis sebagai platform yang baik untuk membangun multicarrier berbasis waveform. Akansu et.al. menekankan hubungan antara filterbank dan teori multiplexer dan memprediksikan bahwa OWDM mempunyai kemampuan umtuk bermain di sistem komunikasi yang akan datang [1]. Pada sistem OWDM, Inverse Fast Fourrier Transform dan Fast Fourrier Transform digantikan dengan Inverse Discrete Wavelet Transform dan Discrete Wavelet Transform [8]. Pada Penelitian ini akan membandingkan power spectral density dari kedua sistem yaitu OFDM dan OWDM.

\section{LANDASAN TEORI}

\subsection{Orthogonal Wavelet Division Multiplexing (OWDM)}

Orthogonal wavelet Division Multiflexing (OWDM) adalah suatu multicarrier technique alternatif dari Orthogonal Frequency Division Multiflexing (OFDM). OWDM dalam sistem komunikasi terdiri dari proses sintesa sinyal yang berupa filter bank dengan multiple input dan satu output pada transmitter .Masing-masing input merupakan sub-simbol dari superymbol sebagai keluaran dari skema modulasi. Sedangkan output merupakan sinyal OWDM yang merepresentasikan supersymbol. Proses sintesa menghasilkan sinyal OWDM sebagai kombinasi dari pulsa-pulsa OWDM weighted. Masing-masing pulsa OWDM weighted merupakan representasi dari simbol . Pada receiver dilakukan proses analisis sinyal menggunkan filter bank, dengan input satu dan multiple output.

\subsection{Transformasi Wavelet Diskrit}

\subsubsection{Transformasi Wavelet Diskrit Maju (Forward DWT) [3][6]}

Pada transformasi wavelet diskrit, representasi sinyal digital diperoleh dengan menggunakan teknik filtering digital. Filter dengan frekuensi cut-off berbeda digunakan untuk menganalisa sinyal pada skala yang berbeda. Sinyal dilewatkan ke dalam rangkaian High Pass Filter (HPF) dan Low Pass Filter (LPF) untuk menganalisa frekuensi tinggi dan frekuensi rendah. Resolusi sinyal merupakan ukuran jumlah informasi detail dari sinyal diubah dengan operasi filtering sedangkan skala diubah dengan operasi dowmsampling dan upsampling(sub sampling). Subsampling sinyal yang berarti menurunkan sampling rate atau membuang beberapa sampel sinyal. Upsampling sinyal yang berarti menaikkan sampling rate sinyal dengan menambahkan sampel-sampel baru ke dalam sinyal. Dikarenakan pembagian filtering yang tidak simetris untuk setiap sub-band sebelumnya, maka pembagian bandwitdh per sub-band tidak sama. Dapat dijelaskan pada gambar dibawah ini, diilustrasikan dimana sinyal $\mathrm{x}[\mathrm{n}]$ merupakan sinyal asli akan dilakukan dekomposisi dengan $\mathrm{h}[\mathrm{n}]$ dan $\mathrm{g}[\mathrm{n}]$. Bandwitdh untuk setiap sinyal ditandai dengan $\mathrm{f}$. 


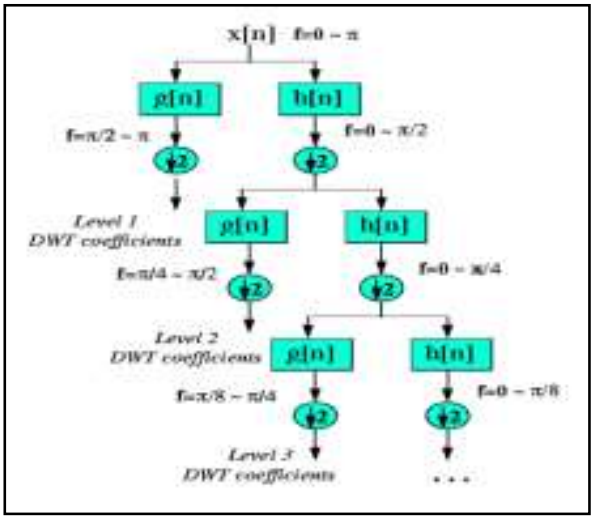

Gambar 1. Prosedur Proses Dekomposisi sinyal dengan Discrete Wavelet Transform

Dari Gambar 1 dapat dijelaskan prosedur dari Discrete Wavelet Ttransform adalah:

- Sinyal dilewatkan ke HPF dan LPF, masing-masing untuk menganalisa sinyal frekuensi tinggi dan frekuensi rendah. Filtering di sini sesuai dengan operasi konvolusi sinyal dengan respon impuls filter.

$$
x[n] * h[n]=\sum_{-\infty}^{\infty} x[k] . h[n-k]
$$

- Setelah sinyal melalui LPF dan HPF, dilakukan subsampling dengan faktor 2. Secara matematis dapat dituliskan:

$$
y[n]=\sum_{-\infty}^{\infty} h[k] \cdot x[2 n-k]
$$

- DWT menganalisa sinyal pada band frekuensi dan resolusi yang berbeda. Dekomposisi sinyal menghasilkan koefisien detil dan koefisien aproksimasi. DWT terdiri dari 2 set fungsi yaitu scaling function dan wavelet function yang terdiri dari proses filtering HPF dan LPF serta up/down sampling. Sinyal asli $\mathrm{x}[\mathrm{n}]$ pertama kali di lewatkan ke HPF g[n] dan LPF h[n]. Setelah proses filtering, keluaran masing-masing filter dilakukan subsampling dengan faktor 2. Sinyal keluaran proses dekomposisi untuk setiap level secara matematis dapat ditulis :

$$
\begin{aligned}
& y_{\text {high }}[k]=\sum_{-\infty}^{\infty} x[n] \cdot g[2 k-n] \\
& y_{\text {low }}[k]=\sum_{-\infty}^{\infty} x[n] \cdot h[2 k-n]
\end{aligned}
$$

- Hubungan HPF dan LPF dilihat dari persamaan :

$$
g[L-1-n]=(-1)^{n} \cdot h[n]
$$

Dimana $L$ adalah panjang filter.

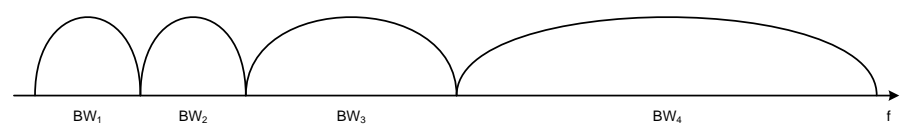

(a) 


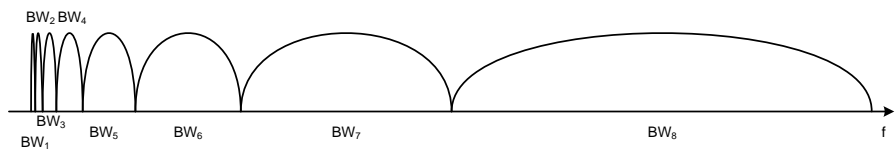

(b)

Gambar 2. Pembagian Bandwidth: (a) 4 sub-band, (b) 8 sub-band

\subsubsection{Transformasi Wavelet Diskrit Balik (IDWT) [3][6]}

Proses rekonstruksi dilakukan pada blok ini yaitu dengan proses upsampling dan filtering.

Prosedur dari IDWT adalah:

- Sinyal pada setiap level dilakukan upsampling oleh faktor 2, lalu dilewatkan ke sintesis filter highpass dan kemudian dijumlahk dimana upsampling dilakukan untuk menggabungkan sinyal.

- Persamaan rekonstruksi dapat dituliskan :

$$
x[n]=\sum_{-\infty}^{\infty}\left(y_{\text {high }}[k] \cdot g[2 k-n]\right)+\sum_{-\infty}^{\infty}\left(y_{\text {high }}[k] \cdot g[2 k-n]\right)
$$

- Fiilter yang memberikan rekonstruksi yang sempurna salah satunya yaitu filter wavelet yang dikembangkan oleh Ingrid Daubechies yang disebut dengan wavelet Daubechies.

\subsection{Orthogonal Frequency Division Multiflexing (OFDM)}

Orthogonal Frequency Division Multiplexing (OFDM) merupakan teknik modulasi multicarrier yang menggunakan frekuensi saling tegak lurus sebagai solusi untuk mengatasi permasalahan multipath fading. Orthogonalitas pada OFDM memperbolehkan transmisi secara simultan pada sub-carrier pada band frekuensi yang terbatas tanpa terjadi interferensi.

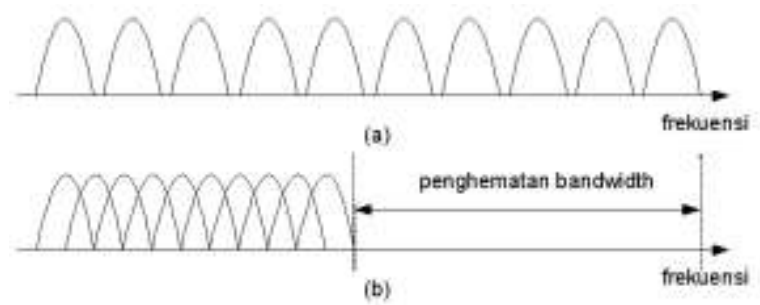

Gambar 3. Spektrum multicarrier (a) tanpa overlapping, (b) dengan Overlapping

\section{PEMBAHASAN}

\subsection{Pemodelan Sistem OWDM dan OFDM}

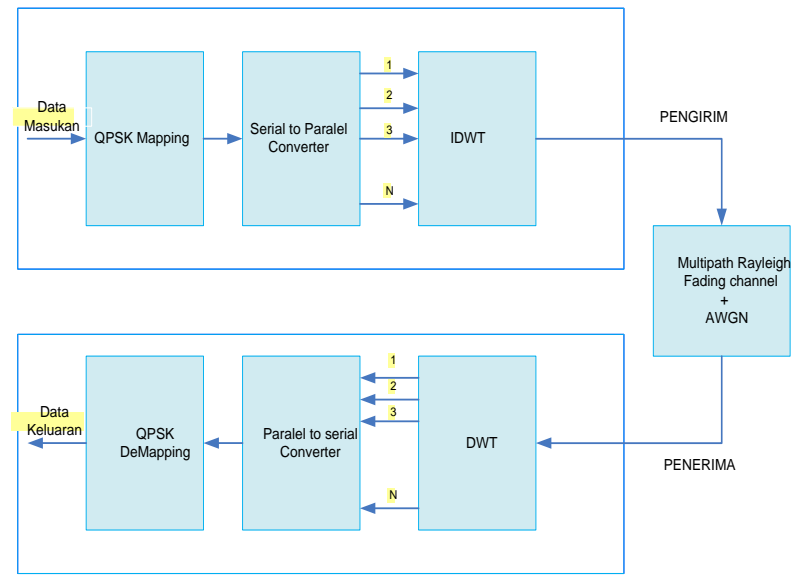

Gambar 4. Pemodelan Sistem OWDM menggunakan Transformasi Wavelet Diskrit 
Pemodelan Sistem OWDM menggunakan wavelet diskrit ditunjukkan oleh Gambar.4. Data input yang dibangkitkan oleh generator data kemudian dipetakan menggunakan QPSK menghasilkan simbol-simbol dengan 4 variasi simbol yg berbeda fasa. Blok Serial to Parallel Converter digunakan untuk membagi data keluaran mapper menjadi beberapa data paralel yang disesuaikan dengan jumlah sub-band/ lengan/ level dari proses reconstruction filter bank (IDWT). Kemudian keluaran Pengirim ditransmisikan memalui kanal AWGN dan kanal rayleigh menuju ke penerima. Proses di penerima adalah kebalikan dari pengirim, proses decomposition filter bank digunakan untuk mendapatkan kembali simbol-simbol yang dikirim.

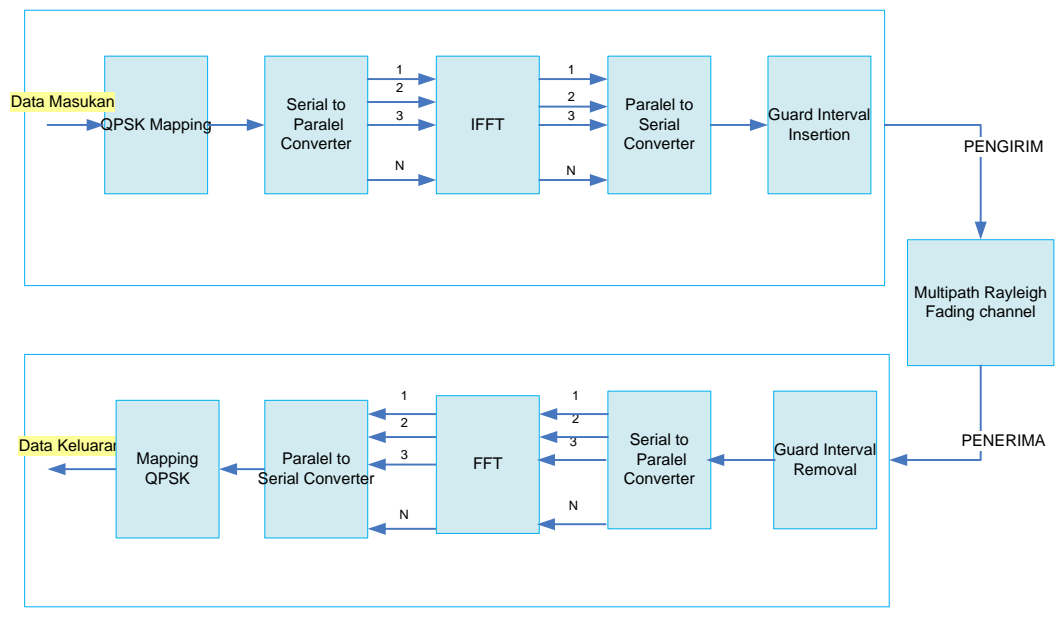

Gambar 5. Pemodelan Sistem OFDM

Gambar 5. menunjukkan pemodelan dari sistem OFDM. IFFT digunakan untuk membuat ortogonalitas antara sub-carrier sehingga spektrum sub-carrier dapat dibuat saling tumpang tindih dalam domain frekuensi tanpa saling berinteferensi. Penambahan Guard Interval pada awal simbol OFDM digunakan untuk menghilangkan efek ISI . Guard interval ini merupakan replika dari deretan akhir simbol OFDM yang disebut dengan cyclic prefix. FFT melakukan konversi dari sinyal OFDM dalam bentuk deretan simbol-simbol menjadi bilangan-bilangan kompleks sesuai dengan konstelasi mapping QPSK pada pengirim. Berikut adalah tabel parameter simulasi untuk sistem OWDM dan OFDM.

Tabel 1. Parameter sistem OWDM dan OFDM

\begin{tabular}{|l|l|}
\hline PARAMETER & Jenis Parameter \\
\hline Jenis Modulasi & QPSK \\
\hline $\begin{array}{l}\text { Jumlah sub-band/sub-carrier } \\
(\mathrm{N})\end{array}$ & 16 \\
\hline Model kanal & $\begin{array}{l}\text { AWGN + Multipath } \\
\text { Rayleigh Fading }\end{array}$ \\
\hline Bandwidth $(\mathrm{BW})$ & $2 \mathrm{MHz}$ \\
\hline Delay spread $\left(\sigma_{\tau}\right)$ & $200 \mathrm{~ns}$ \\
\hline Kecepatan User $(\mathrm{v})$ & $3 \mathrm{~km} / \mathrm{jam}$ \\
\hline Jumlah Bit yang ditransmisikan & $2^{\wedge} 16$ \\
\hline Filter Wavelet & $\mathrm{db} 8$ \\
\hline
\end{tabular}




\subsection{Analisa Hasil Simulasi}

Berikut adalah hasil simulasi yang diperoleh untuk sistem OWDM dan OFDM pada kanal rayleigh.

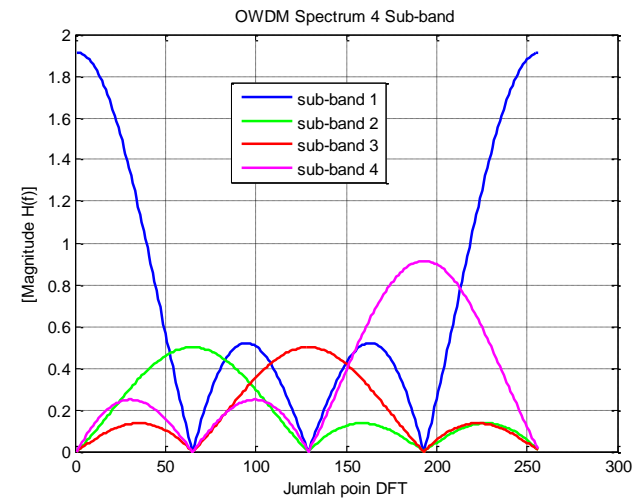

Gambar 6. Spektral sinyal OWDM 4 sub-band

Pada sistem OWDM menggunakan wavelet diskrit, masing-masing sub-band memiliki band frekuensi yang berbeda, kecuali untuk sub-band pada level yang sama. Gambar .6 memperlihatkan pembagian band frekuensi untuk 4 sub-band (3 level IDWT). Pembagian frekuensi subband diperlihatkan pada tabel berikut:

Tabel 2. Pembagian band frekuensi 4 sub-band

\begin{tabular}{|c|c|}
\hline Sub-band & $|H(f)|$ \\
\hline 1 (level 1 IDWT) & 1.9 \\
\hline 2 (Level 2 IDWT) & 0.95 \\
\hline 3 (level 3 IDWT) & 0.475 \\
\hline 4 (level 3 IDWT) & 0.475 \\
\hline
\end{tabular}

Penggunaan IDWT pada sistem OWDM yang menyebabkan antara sub-band/sub-carrier memiliki band frekuensi yang tidak sama. Hal ini berpengaruh terhadap semakin lebar band frekuensi dari suatu sub-band maka akan ada kemungkinan kanal masih terasa frekuensi selektif fading. Hal ini terjadi jika bandwidth sub-band sinyal melewati bandwidth koheren kanal yang lebih sempit. Bandwidth koheren kanal akan semakin sempit jika nilai delay spread semakin tinggi.

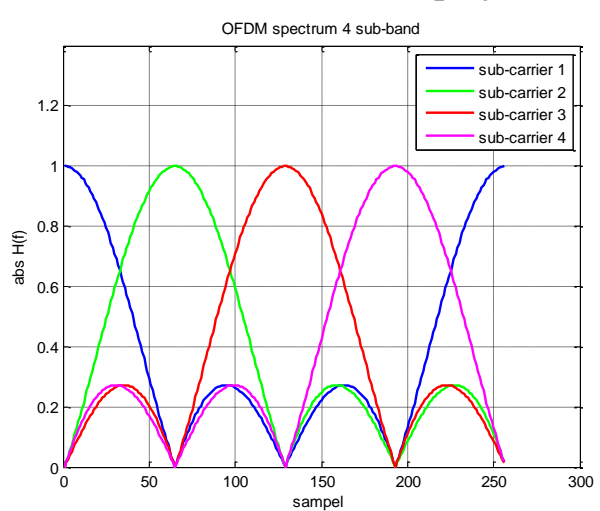

Gambar 7. Spektral sinyal OFDM 4 sub-carrier 
Pada Gambar.7 memperlihatkan spektrum band frekuensi untuk sistem OFDM 4 subcarrier. Di sini terlihat bahwa, dalam sistem OFDM setiap sub-band mempunyai band frekuensi yang sama.

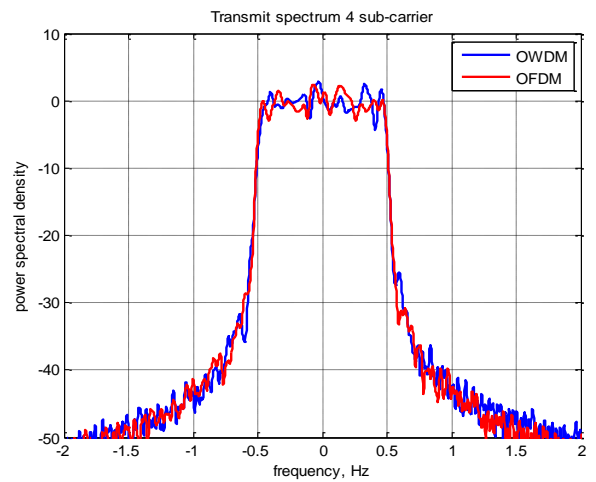

Gambar 8. Power Spectral Density sistem OWDM dan OFDM

Grafik perbandingan PSD sistem OWDM dan OFDM pada Gambar 6, 7 dan 8 memperlihatkan bahwa power spectrum density untuk sub-band 4 untuk kedua sistem adalah sama. Akan tetapi, pada sistem OWDM bandwidth untuk masing-masing sub-band berbeda. Semakin tinggi level sub-band maka semakin lebar band frekuensinya.

\section{KESIMPULAN}

Dari hasil simulasi perbandingan power spectral density (PSD) antara sistem OWDM dan OFDM, dapat disimpulkan bahwa kedua sistem memiliki nilai PSD yang sama. Akan tetapi pembagian bandwidth untuk masing-masing subband sistem OWDM berbeda.

\section{Daftar Pustaka:}

[1] Hassen, S.Fadel.2008.The Performance of Orthogonal wavelet Division Multiplexing $(O W D M)$ in Flat Rayleigh Fading Channel. Journal of Engineering and Development, Vol .12, No.1.

[2] Nerma, Mohamed,H.M., Kamel, Nidal.S and Jeoti, Varun.An OFDM System Based on Dual Tree Complex Wavelet Transform (DT-CWT). Signal Processing: An International Journal (SPIJ), Volume(3) : Issue(2).

[3] Polikar, R.1995. The Wavelet Tutorial. Department of Electrical and Computer Engineering, Rowan University.

[4] Ahmed, Nadeem.2000. Joint Detection Strategies for Ortoghonal Division Multiplexing. Thesis Master of Science. Texas.

[5] Strang, Gilbert., Nguyen, Truong.Wavelet and Filter banks. Wellesley. Cambridge Press.

[6] Burrus, C. Sidney.,Gopinath, Ramesh A and Guo, Haitao.1998. Introduction to wavelet and Wavelet Transform A Primer. Prentice-Hall, Inc.

[7] Dinata, irwan. Analisa Power Spectral Density pada Sistem Orthogonal Wavelet Division Multiplexing Berbasis Wavelet Packet. Elektronik Jurnal Arus Elektro Indonesia (eJAEI)

[8] Rappaport,Theodore.S.1999.Wireless Communications Principle and Practice.

[9] Silanders, Anders.1999. On Wavelet For Digital Communication. Thesis for The Degree of Licentiate of Philosophy. Sweden.

[10] Scott L. Linfoot, Mohammad K. Ibrahim, Marwan M. Al-Akaidi.2007. Orthogonal Wavelet Division Multiplex: An Alternative to OFDM. IEEE Transactions on Consumer Electronics, Vol. 53, No. 2. 
[11] Tabassum Nawaz Bajwa, Arsla Khan, Sobia Baig. 2011. Evolution of Orthogonal Frequency Division Multiplexing Modulation to Discrete Wavelet Multitone. Frontiers of Information Technology. 978-0-7695-4625-4/11 C 2011 IEEE. DOI 10.1109/FIT.2011.1963.

[12] Avila. J, Vinoth. B, Thenmozhi. K.2013. DWT \& FEC guided Orthogonal Frequency Division Multiplexing (MB-OFDM)- Enhanced Quality Data Rate. Proceedings of 2013 IEEE Conference on Information and Communication Technologies (ICT 2013).

[13] N.R.Raaj an, B.Monisha, M.Ram Kumar, A.Jenifer Philomina, M.V.Priya, D.Parthiban, S.Suganya.2011. Design and Implementation of Orthogonal Wavelet Division Multiplexing (OHWDM) with Minimum Bit Error Rate. 978-1-4673-0132-91111.IEEE.

[14] Abdullah S. Almuttiri Scott L. Linfoot.2013. Orthogonal Wavelet Division Multiplex as a Modulation Scheme for Digital Television. IEEE Third International Conference on Consumer Electronics - Berlin (ICCE-Berlin).

[15] A.Vamsidhar. 2016. Performance Comparison of FFT and DWT based MIMO-OFDM Communication Systems. International Journal of Modern TRends in Engineering and Research. 